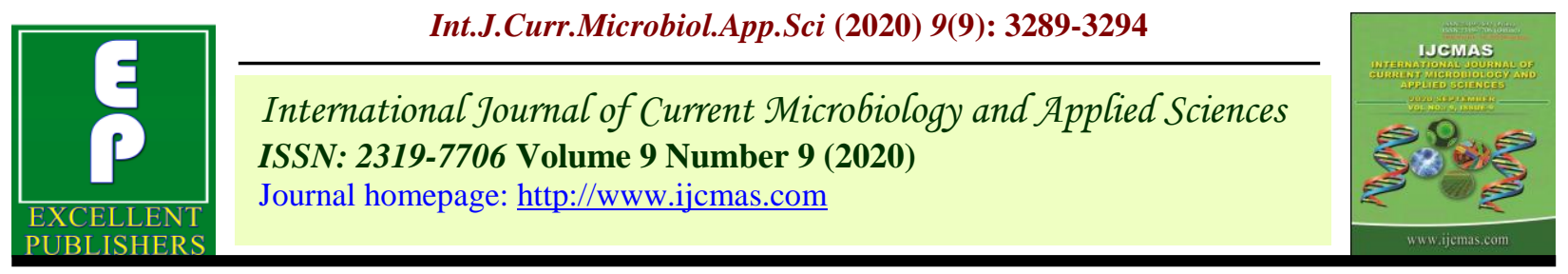

\title{
Extent of Information and Communication Technology (ICT) Exposure of Dairy Farmers in Morar Block of Gwalior District
}

\author{
Nemi Chand Meena ${ }^{1 *}$, S. K. Badodiya ${ }^{2}$ and Diksha Sharma ${ }^{1}$ \\ ${ }^{1}$ Swami Keshwanand Rajasthan Agricultural University, Bikaner, India \\ ${ }^{2}$ KVK Senior Scientist and Head, Badwani, Madhya Pradesh, India \\ *Corresponding author
}

Keywords

Extent, Dairy farmers, ICT, Exposure

Article Info

Accepted:

24 August 2020 Available Online:

10 September 2020

\begin{abstract}
A B S T R A C T
The present study was conducted to assess the extent of ICT exposure of dairy farmers in Morar Block of Gwalior district, Madhya Pradesh. Simple random sampling method was used to select 120 dairy farmers as respondents. The extent of ICT exposure referred to the frequency of listening to radio broadcast, viewing to television telecast, viewing to krishi mela, using internet, reading newspaper and farm magazines regarding information on improved practices of animal husbandry The study revealed that more than half $(52.50 \%)$ of the dairy farmers had medium level of ICT exposure regarding improved animal husbandry practices. The profile variables such as education $(0.668)$, social participation (0.337), annual income (0.326), extension participation (0.283), source of information (0.301), risk orientation (0.248), knowledge about animal husbandry practices $(0.371)$ and adoption of animal husbandry practices (0.301) were found to be positively significant with the extent of ICT exposure whereas age (0.087) was non-significant.
\end{abstract}

\section{Introduction}

India, being a predominantly agricultural country the foundation for prosperity lies on agricultural production as well as on dairy farming has been well recognized. India occupies the foremost position in respect of livestock where keeping milch animals has been never a separate occupation from agriculture. Thus, its rural economy is closely associated with dairy farming which plays a vital role in economy of our country. It also helps in augmenting food supply, generating employment and raising nutritional level. In rural areas of Gwalior district, the agricultural production and animal husbandry are mainly in the hands of the farming community, who maintain one or two milch animals under twotier production system and maintain them on the by-products of the agricultural produces. Due to limited resources available with the farming community, expected improvement is yet to achieve by them in the milk production per animal. The availability of latest scientific knowledge of dairy farming, which is based on four pillars namely, innovative breeding, balanced feeding, excellent management and well supervised health control of cattle and buffaloes, are the major elements to create ideal and expected conditions in animal 
husbandry. To transfer the latest technological know-how to the ultimate users, different communication media are available.

In present information age, the communication services, especially the information communication technology have been designed to support the national development in an alliance for the progress. They are designed to help the farming community to improve its productive capabilities and its overall quality of life. There is a need of knowing the relative effectiveness of mass communication media and influence of farmer's background factors on the effectiveness of such communication media. Due to this the question arises why the dairy farmers are not yet able to reach expected level of adoption of improved animal husbandry practices. To answer this, the present study was conducted with the following objectives include to study the extent of ICT exposure of dairy farmer in Morar block, Gwalior District and to ascertain relationship between the profile of dairy farmers and their extent of ICT exposure.

\section{Materials and Methods}

Morar Block of Gwalior district in the state of Madhya Pradesh was selected as the study area due to the presence of maximum dairy farmers in the block. The selected block comprises of 176 villages. A list of villages where animal husbandry practices are being operated by the farmers was prepared with help of extension officials. Out of which, 10 villages were selected randomly by using the sampling method for the study. A total of 120 dairy farmers as respondents were selected by simple random sampling. The extent of ICT exposure of dairy farmers was referred to the frequency of listening to radio broadcast, viewing to television telecast, viewing to krishi mela, using internet, reading newspaper \& farm magazines. This variable was quantified by using following procedure. To study the extent of ICT exposure of the respondents, a structure schedule was developed. Score of two for regular participation (exposure), one for occasional participation and zero for non- participation, were assigned separately for newspaper, radio broadcasts, farm literature, television programme and use of internet relating to animal husbandry practices. It was measured with the score assigned to each statement. Based on the scores, the respondents were classified into the three categories viz., low, medium and high by using mean and standard deviation as a measure of check. The selected profile variables included social-personal characteristics (age, education and social participation), socio-economic characteristics (annual income), communication characteristics (extension participation, source of information) and psychological characteristics (risk orientation, knowledge about animal husbandry and adoption of animal husbandry practices). The data collected was analysed using statistical tools like frequency, percentage and Karl Pearson's Correlation coefficient.

\section{Results and Discussion}

\section{Profile of dairy farmers}

The data presented in Table 1 reveals the social-personal, socio-economic, communication and psychological characteristics of the dairy farmers. The data reveals that majority (55.83 per cent) of the respondents were found in the middle age group. Almost similar findings were also reported by G.P. Sabapara et al., (2016) and Verma et al., (2016). Table 1 also reveals that most of the respondents $(37.50 \%)$ were educated up to middle school level. Further perusal reveals that majority of respondents 50.00 per cent had medium social participation; similar findings were also reported by Aulakh and Singh (2012) and Sabapara et al., (2016). 
Regarding annual income the table reveals that the maximum of the respondents (52.50\%) belonged to 'medium' income group. Out of the total 120 respondents, 42.50 per cent had medium extension participation and 55.80 per cent respondents were found to be in medium source of information. 75.00 per cent respondents were found to be in medium risk orientation category. More than half $(54.17 \%)$ of the milk producers had medium level of knowledge regarding improved animal husbandry practices; similar findings were found by Aulakh and Singh (2012) and Sabapara et al., (2016).

Lastly more than half (58.33 per cent) of the milk producer had medium level of adoption of improved animal husbandry practices. The finding is in agreement with findings of Aulakh and Singh (2012), Sabapara et al., (2016).

\section{Extent of ICT exposure of dairy farmers}

Communication exposure helps people to gain general awareness as well as provides scientific and technical information and plays an important role to improve socio-techno economic standards. ICT exposure referred to the frequency of listening to radio broadcast, viewing to television telecast, viewing to krishi mela, using internet, reading newspaper and farm magazines regarding information on improved practices of animal husbandry.

The findings are presented in Table 2 . Regarding use of internet, that majority $(58.33 \%)$ of the respondents were not using the internet facilities. With regards to listening to radio, majority $(54.17 \%)$ of the respondents were irregular in listening to radio broadcast. In case of viewing television, majority $(55.00 \%)$ of the respondents regularly viewed the television. Regarding participation in Krishi mela/exhibition, majority $(54.17 \%)$ of the respondents irregularly participated in such extension activities regarding improved animal husbandry practices. With regards to using newspaper and farm magazines, majority (47.50\%) of the respondents were irregularly reading the newspaper and farm magazines.

\section{Overall extent of ICT exposure of dairy farmers}

The information regarding ICT exposure was collected as the nature and frequency of respondent's involvement in different mass media such as newspaper \& farm magazines, radio, television, krishi mela/exhibition, and use of internet facility. The respondents were classified in to three categories as shown in Table 3.

The findings reveals that more than half (52.50 per cent) of the respondents were having medium level of ICT exposure, followed by one-fourth (30.00 per cent) with low and slightly less than one-sixth (17.50 per cent) had high level of ICT exposure. This might be due to their low to medium level of awareness regarding importance of various tools of ICT in improving their knowledge.

As a result of this they might not have shown their expected interest in useful programmes broadcasted and telecasted on radio and television, respectively, as well as farm literature and newspaper published by different agencies.

The finding of this study is in conformity with the findings observed by Iorliam et al., (2012) Kafura et al., (2016). 
Table.1 Distribution of respondents according to their profile variables $(n=120)$

\begin{tabular}{|c|c|c|}
\hline Categories & Frequency & Percentage \\
\hline \multicolumn{3}{|l|}{ Age } \\
\hline Young & 33 & 27.50 \\
\hline Middle & 67 & 55.83 \\
\hline Old & 20 & 16.67 \\
\hline \multicolumn{3}{|l|}{ Education } \\
\hline Illiterate & 10 & 08.33 \\
\hline Primary school & 40 & 33.33 \\
\hline Middle school & 45 & 37.50 \\
\hline High School & 14 & 11.67 \\
\hline Above high school & 11 & 09.17 \\
\hline Low & 15 & 12.50 \\
\hline Medium & 60 & 50.00 \\
\hline High & 45 & 37.50 \\
\hline \multicolumn{3}{|l|}{ Social Participation } \\
\hline Low & 15 & 12.50 \\
\hline Medium & 60 & 50.00 \\
\hline High & 45 & 37.50 \\
\hline \multicolumn{3}{|l|}{ Annual Income } \\
\hline Low (<1.19 score) & 36 & 30.00 \\
\hline Medium (1.19 to 2.55 score) & 63 & 52.50 \\
\hline High (>2.55 score) & 21 & 17.50 \\
\hline \multicolumn{3}{|l|}{ Extension participation } \\
\hline Low $(<1.29$ score $)$ & 31 & 25.80 \\
\hline Medium (1.29 to 2.81 score) & 51 & 42.50 \\
\hline High (>2.81 score) & 38 & 31.70 \\
\hline \multicolumn{3}{|l|}{ Source of information } \\
\hline Low $(<2.41$ score $)$ & 27 & 22.50 \\
\hline Medium (2.41 to 6.45 score) & 67 & 55.80 \\
\hline High (>6.45 score) & 26 & 21.70 \\
\hline \multicolumn{3}{|l|}{ Risk Orientation } \\
\hline Low $(<2.70$ score $)$ & 15 & 12.50 \\
\hline Medium (2.70 to 7.02 score) & 90 & 75.00 \\
\hline High (>7.02 score) & 15 & 12.50 \\
\hline \multicolumn{3}{|c|}{ Knowledge level about animal husbandry practices } \\
\hline Low $(<4.83$ score $)$ & 15 & 12.50 \\
\hline Medium (between 4.83 to 8.03 score) & 65 & 54.17 \\
\hline High (> 8.03 score) & 40 & 33.33 \\
\hline \multicolumn{3}{|c|}{ Adoption level of improved animal husbandry practices } \\
\hline Low $(<3.63$ score $)$ & 18 & 15.00 \\
\hline Medium (between 3.63 to 6.21 score) & 70 & 58.33 \\
\hline High (> 6.21 score $)$ & 32 & 26.67 \\
\hline
\end{tabular}


Table.2 Extent of ICT exposure regarding improved practices of animal husbandry $(n=120)$

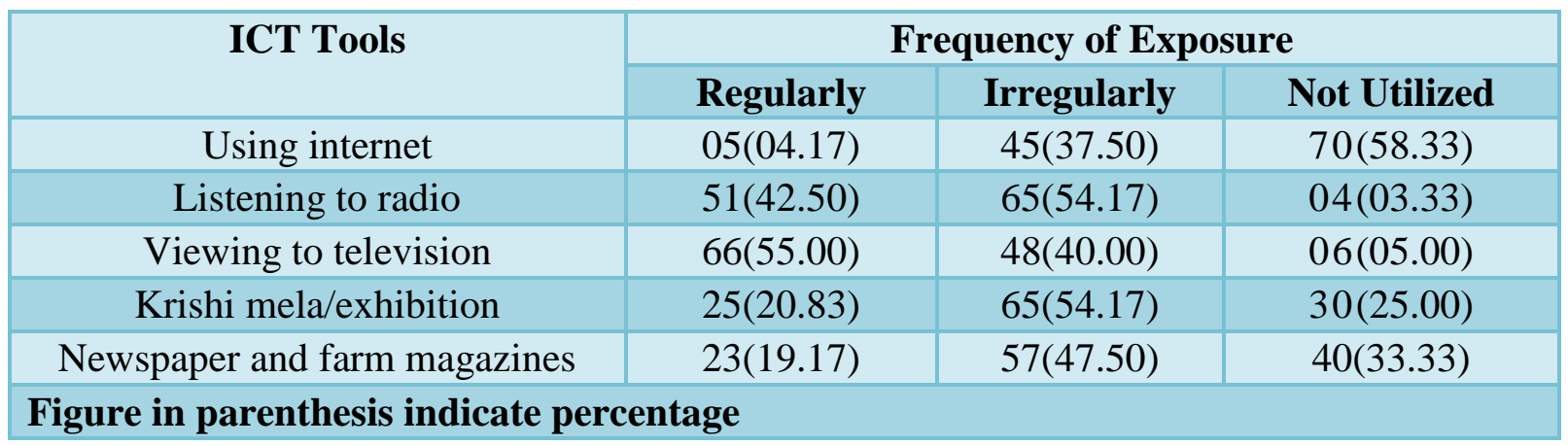

Table.3 Distribution of dairy farmers according to their overall ICT exposure $(n=120)$

\begin{tabular}{|c|c|c|}
\hline Level of ICT exposure & Frequency & Percentage \\
\hline Low $(<1.19$ score $)$ & 36 & 30.00 \\
\hline Medium (between 1.19 to 2.55 score $)$ & 63 & 52.50 \\
\hline High $(>2.55$ score $)$ & 21 & 17.50 \\
\hline Mean $(\overline{\mathrm{x}})=1.87$ & SD $=0.68$ & \\
\hline
\end{tabular}

Table.4 Relationship between the profile of dairy farmers and their extent of ICT exposure $(n=120)$

\begin{tabular}{|c|c|}
\hline Particulars & Correlation coefficient \\
\hline Age & $\mathbf{0 . 0 8 7}{ }^{\text {NS }}$ \\
\hline Education & $\mathbf{0 . 4 6 8 * *}$ \\
\hline Social participation & $\mathbf{0 . 3 3 7 * *}$ \\
\hline Annual income & $\mathbf{0 . 3 2 6 * *}$ \\
\hline Extension participation & $\mathbf{0 . 2 8 3} * *$ \\
\hline Source of information & $\mathbf{0 . 3 0 1} * *$ \\
\hline Risk orientation & $\mathbf{0 . 2 4 8 * *}$ \\
\hline Knowledge about animal husbandry Practices & $\mathbf{0 . 3 7 1} * *$ \\
\hline Adoption of animal husbandry practices & $\mathbf{0 . 3 0 1} * *$ \\
\hline
\end{tabular}

* Significant at $1 \%$ level of probability ** Significant at $5 \%$ level of probability NS = Non Significant

Relationship between the profile of dairy farmers and their extent of ICT exposure

The profile variables were correlated with the extent of ICT exposure of dairy farmers using Karl Pearson's Correlation coefficient. It can be observed from Table 4 that correlation coefficients in respect of education (0.668), social participation (0.337), annual income (0.326), extension participation (0.283), source of information (0.301), risk orientation (0.248), knowledge about animal husbandry practices (0.371) and adoption of animal husbandry practices (0.301) were found to be positively significant with the extent of ICT exposure whereas age (0.087) was found non-significant; 
similar findings regarding age were also reported by Singh and Sharma (1973). Also regarding social participation and annual income similar findings were reported by Verma et al., (12016).

It can be concluded from the study that that more than half of the dairy farmers had medium level of ICT exposure regarding improved animal husbandry practices. It was noticed that low to medium level of awareness regarding importance of various tools of ICT in improving their knowledge regarding useful programmes broadcasted and telecasted on radio and television, respectively, as well as farm literature and newspaper published by different agencies resulted in medium level of ICT exposure of the dairy farmers in Morar block.

Based on the findings and observations, the following recommendations are made to improve the ICT exposure of the dairy farmers:

Extension contact and social participation of the dairy farmers showed their significant influences. It is therefore, recommended that the dairy farmers who are not members of any useful organizations should be persuaded to get enrolled as an active member and village extension worker should visit regularly and frequently and motivates them.

Priority should be given to improve the existing level of adoption and knowledge regarding improved animal husbandry practices of the dairy farmers.

Conducting motivational tour programmes, demonstrations as well as by providing on campus institutional training programmes on improve animal husbandry practices to dairy farmers motivate them to adopt improved animal husbandry practices.

Create or organise awareness programmes on use of various ICT tools for easy asses to good quality animal husbandry practices for rearing of dairy animals.

\section{References}

Aulakh G.S. and Sharma K. (2012). Studies on adoption of recommended buffalo breeding practices in Punjab. Indian Research Journal of Extension Education, 12(1): 20-22.

Sabapara G. P., Fulsounda A. B. and Kharadi V. B. (2016) Profile of Dairy Farmers and Relationship with Adoption of Improved Dairy Husbandry Practices in Southern Gujarat, India. Livestock Res. Inter., 4 (1): $36-40$

Iorliam, T., Imbur, E.N. and Iortima, P. (2012) Adoption of information and communication technologies as source of information on agricultural innovations among farm households in Nigeria: Evidence from Benue state. Inter. J. of Development and Sustainability. 1(3):924-931

Kafura, R.A., Afrad, M.D.S.I., Prodhan, F.A. and Chakraborty, D. B. (2016) Use of ICT as Extension tool by the Farmers of Gazipur district in Bangladesh. Indian Res. J. Ext. Edu., 16(2).

Verma A.P., Ansari, M.A., Ranjan R., Bhatt Archana., Raghuvanshi Rupan and Patel Diksha (2016) Farmers' Attitude towards E-Choupal: A Critical Investigation in Gonda district of Uttar Pradesh. International Journal of Agriculture Sciences, 8(49): 2076-2078.

\section{How to cite this article:}

Nemi Chand Meena, S. K. Badodiya and Diksha Sharma. 2020. Extent of Information and Communication Technology (ICT) Exposure of Dairy Farmers in Morar Block of Gwalior District. Int.J.Curr.Microbiol.App.Sci. 9(09): 3289-3294. doi: https://doi.org/10.20546/ijcmas.2020.909.408 